\title{
AVALIAÇÃO DA VIDA-DE-PRATELEIRA DE MORANGOS RECOBERTOS COM BIOFILME DE ACETATO DE AMIDO E ACETATO DE AMIDO COM ADIÇÃO DE SORBATO DE POTÁSSIO
}

\author{
M. C. R. da SILVA $^{1}$ e V. C. R. SCHMIDT ${ }^{1}$ \\ ${ }^{1}$ Universidade Federal de Uberlândia, Faculdade de Engenharia Química \\ E-mail para contato: vivian@feq.ufu.br
}

\begin{abstract}
RESUMO - O morango é uma fruta muito perecível, assim, a sua comercialização tem muitos desafios. Embalagens são uma excelente forma de conservação. Com isso, recobrir os frutos com biofilme de acetato de amido é uma alternativa para resolver o problema. Com associação de conservantes, como sorbato de potássio, é esperado maior extensão da vida-útil. Diante disso, o objetivo deste trabalho foi avaliar o comportamento da vida-de-prateleira de morangos recobertos com acetato de amido de mandioca adicionado ou não sorbato de potássio, utilizando morangos sem cobertura como controle, através de análises $\left(\mathrm{pH}\right.$, umidade, $\mathrm{A}_{\mathrm{w}}$, ${ }^{\circ}$ Brix e cor) por 19 dias. No presente trabalho morangos foram recobertos com suspensões preparadas com $3 \mathrm{~g}$ de acetato de amido de mandioca, $100 \mathrm{~g}$ água destilada, glicerol P.A. (0,30 g.g-1 acetato), na suspensão de acetato de amido com sorbato de potássio utilizou-se $0,05 \% \mathrm{~g}$ de sorbato/ $\mathrm{g}$ de acetato de amido, mantendo amostras sem recobrimento como controle. Foi observado que a aplicação de biofilme não interferiu na maturação e na cor das frutas. Para todas as amostras houve um ligeiro aumento no teor de sólidos solúveis e diminuição dos valores atividade de água e teor de umidade. O controle teve perda visual desde o $7^{\circ}$ dia de armazenamento, porém, morangos recobertos perderam a qualidade visual após o $10^{\circ}$ dia. Portanto, biofilmes de acetato de amido são eficazes na extensão da vida-útil de morangos.
\end{abstract}

\section{INTRODUÇÃO}

O morango é uma fruta originalmente de clima temperado (GARCIA, 2009). No Brasil, ela tem se adaptado melhor desde o sul do estado de Minas Gerais até o estado do Rio Grande do Sul (ALCÂNTARA, 2009). Porém, cerca de 40\% da produção é perdida do campo até o consumidor (BRAGA, 2012). A vida útil de morangos mesmo quando armazenados sob refrigeração é normalmente menor a 5 dias. Com isso, a comercialização da fruta se torna um desafio (GARCIA, 2009). Dessa forma, faz-se necessário desenvolvimento de técnicas direcionadas a redução de perdas após a colheita.

Embalagens são uma excelente forma de conservação. No entanto, plásticos convencionais, produzidos a partir de petróleo bruto, ocasionam sérios problemas ambientais após o uso, visto que precisam muito tempo para se degradar. Neste sentido, embalagens 
fabricadas exclusivamente com polímeros naturais, é uma técnica para resolver esse problema, pois podem ser reincorporados ao ambiente em pouco tempo, por serem biodegradáveis (SOUZA et al., 2000).

O amido é uma matéria-prima abundante, de baixo custo e facilmente degradável. Além disso, o amido apresenta muitas possibilidades de modificação química, física ou genética para que possa originar filmes com uma melhor qualidade. Assim, tem um grande potencial de aplicação na produção de biofilmes. Os filmes e coberturas formadas a base de polissacarídeos são pobres barreiras de umidade, mas são boas barreiras de gases apresentando uma permeabilidade seletiva ao oxigênio e gás carbônico (CHI et al., 2008). Dessa forma, estes filmes são muito aplicados no revestimento de frutas, vegetais in natura ou minimamente processados.

A adição de conservantes nessas embalagens é uma forma para estender a vida-deprateleira e melhorar a segurança dos alimentos por combinar a permeabilidade seletiva de gases, da conservação das características sensoriais com ação antimicrobiana. O sorbato de potássio é um conservante químico que evita o crescimento de bolores e leveduras e também atuam contra vários tipos de bactérias, sendo muito utilizado nas indústrias alimentícias (AHMED et al., 2013).

Dessa forma, o objetivo deste trabalho foi avaliar o comportamento da vida-deprateleira de morangos recobertos com acetato de amido de mandioca com adição ou não de sorbato de potássio, utilizando morangos sem cobertura como controle, através de análises físico-químicas ( $\mathrm{pH}$, umidade, $\mathrm{A}_{\mathrm{w}},{ }^{\circ}$ Brix e cor) durante 19 dias de armazenamento.

\section{MATERIAIS E MÉTODOS}

\subsection{Materiais}

Os morangos foram obtidos no comércio local, assim como o Amido de Mandioca da marca Yoki (Yoki Alimentos S.A.). Para a produção de filmes foi utilizado o Glicerol P.A. da marca Synth. Para a produção do acetato de amido foram utilizados o Anidrido Acético P.A. da marca Vetec, Ácido Acético P.A. da marca Dinâmica e Ácido Sulfúrico P.A. da marca Synth. Além desses, foi utilizado sorbato de potássio de uso comercial da marca Doce Aroma.

\subsection{Acetilação do Amido}

Em um béquer de $1000 \mathrm{ml}$ colocou-se $75 \mathrm{~g}$ de amido seco, $135 \mathrm{ml}$ de ácido acético glacial e $138 \mathrm{ml}$ de anidrido acético. A solução foi aquecida a $40^{\circ} \mathrm{C}$ com agitação para assegurar uma mistura completa. Após atingir a temperatura de $40^{\circ} \mathrm{C}$ retirou-se a mistura do aquecimento e foi adicionada cuidadosamente e gradualmente, em banho de gelo com agitação durante os 10 primeiros minutos da reação, a mistura catalisadora (1,05 $\mathrm{ml}$ de ácido sulfúrico concentrado e 12,45 $\mathrm{ml}$ de ácido acético glacial). Em seguida, a solução foi aquecida até atingir a temperatura de reação desejada, mantendo-se a agitação durante 2 horas. Em seguida, foram adicionadas aproximadamente $250 \mathrm{ml}$ de água destilada gelada, para a precipitação do acetato de amido. Após a decantação do precipitado foi realizada a filtração em um filtro de Bücher e o sobrenadante descartado. A secagem do precipitado foi realizada em estufa a $60^{\circ} \mathrm{C}$ por 8 horas. 


\subsection{Preparo dos Filmes, Aplicação e Secagem dos Filmes nos Morangos}

As suspensões de acetato de amido foram preparadas com $3 \mathrm{~g}$ de acetato de amido de mandioca, $100 \mathrm{~g}$ água destilada e glicerol P.A. (0,30 g.g-1 acetato) pesados em uma balança semianalítica (marca Shimadzu). Na suspensão de acetato de amido com sorbato de potássio utilizou-se 0,05\% g de sorbato/ $\mathrm{g}$ de acetato (de acordo com Resolução $\mathrm{n}^{\mathrm{o}} 45$, de 3 de novembro de 2010 - ANVISA). Em seguida, as suspensões foram aquecidas em banho ultratermostatizado (marca Solab), sob agitação mecânica. Após as soluções atingirem $75^{\circ} \mathrm{C}$, foram mantidas por 30 minutos, garantido completa gelatinização. Após o processo, as soluções foram resfriadas à temperatura ambiente.

Estas soluções foram aplicadas nos morangos por submersão da fruta na solução filmogênica, permanecendo imersos por 1 minuto, sendo retirados e colocados em suporte metálico, que foi transferido para uma estufa com circulação ar a temperatura ambiente por 8 horas para secagem da película na superfície do fruto.

\subsection{Avaliação da Qualidade dos Frutos Durante a Estocagem}

Após aplicação dos filmes nas superfícies dos morangos, foram feitas análises de controle de qualidade para acompanhamento do processo de deterioração e comportamento do fruto ao longo dos dias estocados em B.O.D. a $10^{\circ} \mathrm{C}$. Foram realizadas análises de $\mathrm{pH}$, teor de umidade, atividade de água, determinação do ${ }^{\circ}$ Brix e cor ao $0,3^{\circ}, 7^{\circ}, 10^{\circ}, 15^{\circ}$ e $19^{\circ}$ dia de armazenamento.

Determinação de $\mathrm{pH}$ : $\mathrm{O}$ pH foi avaliado através do suco extraído da homogeneização de 3 frutos. A metodologia utilizada foi a descrita pela a AOAC (1999). A leitura foi realizada em pHmetro digital (Marconi).

Teor de Umidade: $\mathrm{O}$ teor de umidade do morango foi determinado pelo método gravimétrico 925.10 sugerido pela AOAC (1999), através do qual a água evaporada em estufa com circulação de ar a $105{ }^{\circ} \mathrm{C}$. O teor de umidade de umidade foi calculado pela Equação 1 , com resultados expressos em porcentagem:

$$
\text { Umidade }=\frac{\text { massa úmida }- \text { massa } \text { seca }}{\text { massa úmida }} \times 100
$$

Atividade de água: Foi realizada a análise de atividade de água utilizando o aparelho Aqualab Lite (marca DECAGON). Primeiramente o aparelho foi calibrado com solução padrão com a faixa de atividade de água próxima do alimento em que seria feita a leitura. Após a calibração, os morangos macerados foram colocados em potes plásticos específicos do equipamento. Em seguida, foram levados ao equipamento para as leituras.

Determinação do ${ }^{\circ}$ Brix: A determinação do ${ }^{\circ}$ Brix foi realizada num refratômetro portátil, com modelo EEQ9029 (marca Edutec). Abriu-se o prisma e limpou-se a superfície usando um lenço de papel umedecido com água destilada. Com o auxílio da pipeta colocou-se algumas gotas de morangos macerados sobre o prisma inferior. Aguardaram-se alguns minutos para que o líquido entrasse em equilíbrio térmico com o prisma. Procurou-se lentamente na ocular a linha de separação entre a região iluminada e a escura, usando para isto 
o botão de variação de ângulo. Com a linha de separação bem nítida procedeu à leitura do ${ }^{\circ}$ Brix.

Análise de cor: A cor foi determinada usando-se um Colorímetro (CR400 - Minolta Company, Tóquio, Japão). Foram realizadas medições em cada uma das 3 frutas que compunham o tratamento, para cada tempo de armazenamento. As coordenadas $\mathrm{L}^{*} \mathrm{a} * \mathrm{~b} *$ foram obtidas pelo espectro de reflexão das amostras utilizando iluminância D65/10 .

\section{RESULTADOS}

No $3^{\circ}$ dia de armazenamento os morangos estavam com ótima cor e sem deterioração microbiológica aparente. No entanto, no $7^{\circ}$ dia de estocagem foi observado que os morangos sem cobertura de filmes (controle) apresentaram perdas visuais consideráveis. A perda de qualidade dos morangos recobertos foi observada no $10^{\circ}$ dia de armazenamento. Deste dia, até ao $19^{\circ}$ dia, observou-se que os morangos foram piorando os aspectos visuais gradativamente.

A Tabela 1 apresenta os resultados da determinação de pH ao longo dos 19 dias. De acordo com os resultados apresentados para o $\mathrm{pH}$, observa-se que não houve variação durante os dias de estocagem para os diferentes testes utilizados. Sendo assim, os valores de $\mathrm{pH}$ ficaram aproximadamente ente 3,0 e 4,0.

Pelas análises realizadas constatou-se que os morangos cobertos com filme de acetato com sorbato de potássio apresentaram menor umidade, quando comparados com os morangos recobertos sem sorbato e ao controle, conforme apresentado na Tabela 1. A umidade do morango decaiu durante os dias de armazenamento para todas as amostras. $\mathrm{O}$ teor de umidade estabelece a quantidade de água. Com isso é possível perceber que o controle possui os maiores valores de umidade. A maior disponibilidade de água facilita o desenvolvimento de microrganismos deteriorantes.

Assim como o teor de umidade, a atividade de água também diminuiu. Pode-se perceber que o controle tem maior atividade, dessa forma, possui mais água livre, ou seja, maior quantidade de água disponível para crescimento microbiano se comparado com os demais frutos. A Tabela 1 apresenta os resultados da atividade de água durante os dias de armazenamento.

Ao contrário do teor de umidade e da atividade de água, o teor de sólidos solúveis ( ${ }^{\circ}$ Brix) aumentou. Isso pode ser explicado pela maior concentração de açúcares devido à maturação ou pela perda de água do produto durante a estocagem. O controle possui os menores valores de ${ }^{\circ}$ Brix, assim, ele possui menos açúcares, sendo menos doce quando comparado aos morangos recobertos com filmes de amido de mandioca e acetato de amido. A Tabela 1 apresenta o comportamento do teor de sólidos solúveis durante os dias de armazenamento. 
Tabela 1 - Resultados das análises de $\mathrm{pH}$, atividade de água (Aw), sólidos solúveis ( $\left.{ }^{\circ} \mathrm{Brix}\right) \mathrm{e}$ umidade para os morangos controle e com recobrimento de filme de acetato amido de mandioca com ou sem adição de sorbato de potássio

\begin{tabular}{cccccccc}
\hline \multirow{2}{*}{ Filmes } & \multirow{2}{*}{ Análises } & \multicolumn{7}{c}{ Dia } \\
\cline { 3 - 8 } & & $0^{\circ}$ & $3^{\circ}$ & $7^{\circ}$ & $10^{\circ}$ & $15^{\circ}$ & $19^{\circ}$ \\
\hline \multirow{5}{*}{ Controle } & $\mathrm{pH}$ & 2,97 & 3,51 & 3,38 & 3,23 & 3,97 & 3,09 \\
& $\mathrm{Aw}$ & 0,975 & 0,993 & 0,980 & 0,988 & 0,976 & 0,956 \\
& ${ }^{\circ} \mathrm{Brix}$ & 5,3 & 5,4 & 6,6 & 7,4 & 7,0 & 10,0 \\
& $\mathrm{Umidade}$ & $93,19 \%$ & $92,49 \%$ & $90,28 \%$ & $90,18 \%$ & $88,89 \%$ & $86,97 \%$ \\
\hline \multirow{2}{*}{ Acetato } & $\mathrm{pH}$ & 3,19 & 3,45 & 3,45 & 3,23 & 3,83 & 3,36 \\
& $\mathrm{Aw}$ & 0,985 & 0,994 & 0,980 & 0,977 & 0,971 & 0,922 \\
& ${ }^{\circ} \mathrm{Brix}$ & 5,6 & 6,8 & 6,3 & 8,1 & 13,7 & 15,3 \\
Acetato & Umidade & $93,45 \%$ & $90,84 \%$ & $90,23 \%$ & $87,87 \%$ & $80,88 \%$ & $80,21 \%$ \\
+ & $\mathrm{pH}$ & 3,49 & 3,25 & 3,46 & 3,31 & 4,04 & 3,14 \\
Sorbato & $\mathrm{Aw}$ & 0,986 & 0,988 & 0,978 & 0,979 & 0,965 & 0,935 \\
& ${ }^{\circ} \mathrm{Brix}$ & 5,4 & 6,7 & 6,6 & 7,9 & 13,4 & 19,4 \\
& Umidade & $93,25 \%$ & $90,68 \%$ & $90,29 \%$ & $88,44 \%$ & $83,73 \%$ & $76,64 \%$ \\
\hline
\end{tabular}

A Tabela 2 apresenta os resultados dos parâmetros de $\Delta \mathrm{L}^{*}, \Delta \mathrm{a}^{*}, \Delta \mathrm{b}^{*}$ e $\Delta \mathrm{E}^{*}$. O espaço de cor CIELAB está organizado em um formulário cúbico, onde o eixo $\mathrm{L}^{*}$ é executado de cima para baixo. Um valor máximo de 100 para $\mathrm{L}^{*}$ representa um perfeito difusor refletindo (Branco). Um valor mínimo de $\mathrm{L}^{*}$ igual a zero representa o preto. Os eixos $\mathrm{a}^{*} \mathrm{e} \mathrm{b}^{*}$ não têm limites numéricos, porém toma-se como referência o valor de 60 unidades de cor, onde $a^{*}$ positivo há uma tendência a vermelho e negativo a verde e $b^{*}$ positivo a amarelo e negativo a azul. Esses valores são frequentemente utilizados no controle de qualidade e ajustes de formulação, além de serem utilizados para o cálculo da diferença total de cor $\left(\Delta \mathrm{E}^{*}\right)$ (HunterLab, 1996). Observa-se que não houve diferença significativa de cor entre as amostras ao nível de significância de 5\%. Sendo assim, apesar o teor de sólidos solúveis ter aumentado e ter ocorrido à perda de massa, nos parâmetros de cor, não ocorreu uma mudança drástica na cor dos frutos.

Tabela 2 - Resultados da análise de cor dos morangos durante 19 dias de armazenamento

\begin{tabular}{ccccc}
\hline \multirow{2}{*}{ Filmes } & \multicolumn{4}{c}{ Parâmetros de Qualidade } \\
\cline { 2 - 5 } & $\Delta \mathrm{L}^{*}$ & $\Delta \mathrm{a}^{*}$ & $\Delta \mathrm{b}^{*}$ & $\Delta \mathrm{E}^{*}$ \\
\hline Controle (sem cobertura) & $1,72 \pm 0,02$ & $-0,24 \pm 0,08$ & $1,15 \pm 0,05$ & 2,0849 \\
\hline Acetato de Amido (ACE) & $1,74 \pm 0,02$ & $-0,31 \pm 0,11$ & $1,16 \pm 0,06$ & 2,1154 \\
\hline ACE com Sorbato de Potássio & $1,75 \pm 0,03$ & $-0,32 \pm 0,06$ & $1,15 \pm 0,06$ & 2,1139
\end{tabular}




\section{CONSIDERAÇÕES FINAIS}

No estudo da vida-de-prateleira de morangos recobertos com biofilmes pode-se concluir que as coberturas comestíveis são eficientes na extensão da vida-útil de morangos armazenados a $10^{\circ} \mathrm{C}$. A vida-útil de morangos sem cobertura foi inferior a 7 dias, já dos morangos recobertos foi de aproximadamente 10 dias. Foi verificado que nos tratamentos que a aplicação de biofilme não interfere na maturação e na cor das frutas. Para todas as amostras houve um ligeiro aumento no teor de sólidos solúveis. A atividade de água e o teor de umidade diminuiu com os dias de estocagem para todas as amostras.

Não houve crescimento de bolor superficial em morangos recobertos o que implica que elas são eficazes no controle de microrganismos deteriorantes. Contudo, a qualidade visual dos morangos recobertos depois do $10^{\circ}$ dia de armazenamento não foi satisfatório. A aparência de frutos com biofilme de acetato de amido de mandioca foi superior aos morangos recobertos com acetato com adição de sorbato de potássio, no entanto, ambos foram inferiores ao controle.

\section{REFERÊNCIAS}

AHMED, Mahmood et al. Sodium Benzoate and Potassium Sorbate in Pakistani Retail Foodstuffs. Inter. J. of Chem., [s.i.], v. 3, n. 6, p.1-6, dez. 2013. Semestral.

ALCÂNTARA, E. M. de. Caracterização física, química e microbiológica de morango, alface e cenoura orgânicos. 2009. 124 f. Dissertação (Mestrado) - Curso de Ciência do Alimentos, Universidade Federal de Lavras, Lavras, 2009.

AOAC - Official Methods of Analysis of AOAC International. 16 th ed., Gaithersburg, 1999.

BRAGA, D. O. Qualidade pós-colheita de morangos orgânicos tratados com óleos essenciais na pré-colheita. 2012. 75 f. Dissertação (Mestrado) - Curso de Ciência do Alimentos, Universidade Federal de Lavras, Lavras, 2012.

CHI, H. et al. Effect of acetylation on the properties of corn starch. Food Chemistry, v. 106, n. 3, p. $923-928$, fev. 2008.

GARCIA, L. C. Aplicação de coberturas comestíveis em morangos minimamente processados. Dissertação. 2009. Programa de Pós-Graduação em Engenharia de Alimentos. Universidade Estadual de Campinas, São Paulo.

HUNTERLAB. CIE $L^{*} a * b *$ color scale: applications note, v.8, n.7, 1996. Acesso em 12 de outubro de 2014. On line. Disponível na internet: http://www.hunterlab.com/color_theory.php

MINOLTA. Precise color communication: color control from feeling to instrumentation. Brasil: MINOLTA Co. Ltda.,1994. 49p.

SOUZA, R. C. R.; ANDRADE, C. T. Investigação do processo de gelatinização e extrusão de amido de milho. Polímeros: Ciên. e Tec., v. 10, n. 1, p.24-30, 2000. 